\title{
La cartografía de la expedición Gilliss al hemisferio sur, Chile 1849 - 1852'
}

\author{
José Ignacio González Leiva² y Germán Hidalgo Hermosilla³
}

\begin{abstract}
RESUMEN
A mediados del siglo XIX, Chile recibió la expedición astronómica naval de los Estados Unidos comandada por el teniente James Melville Gilliss, cuyo propósito respondía al interés de la ciencia universal, como era determinar una nueva medición de la distancia de la Tierra al Sol. Como complemento a su misión principal, Gilliss escribió una descripción de las características físicas, económicas, sociales y políticas del Chile que él conoció durante su permanencia en nuestro país entre 1849 y 1852. Forma parte del documento, un interesante conjunto de planos y mapas de Chile, en gran parte recopilados por el astrónomo, que tienen el mérito de estar confeccionados con las técnicas cartográficas vigentes en ese momento y que ilustran la descripción geográfica del país que le tocó conocer y que quiso mostrar al mundo. A través del análisis de estos materiales, el presente artículo se propone mostrar el aporte de Gilliss en la elaboración de estas cartografías, y cómo todo ello contribuyó a consolidar la identidad de Chile como nación.
\end{abstract}

Palabras Claves: Expedición astronómica, cartografía histórica de Chile, James Melville Gilliss.

\begin{abstract}
In the mid-nineteenth century, Chile received the naval astronomical expedition of the United States commanded by Lieutenant James Melville Gilliss, whose purpose responded to the interest of universal science to determine a new measurement of the distance from Earth to the Sun. As a complement to his main mission, Gilliss wrote a description of the physical, economic, social and political characteristics of Chile that he got to know during his stay in our country between 1849 and 1852. As part of the document there is an interesting set of plans and maps of Chile, largely compiled by the astronomer, which has the merit of being made with the current cartographic techniques that illustrate the geographical description of the country that he got to know and that he wanted to show the world. Through the analysis of these materials, this article aims to show the contribution of Gilliss in the development of these cartographies, and how all this contributed to consolidate the identity of Chile as a nation.
\end{abstract}

Keywords: Astronomical expedition, historical cartography of Chile, James Melville Gilliss.

Este artículo es producto del proyecto de investigación Fondecyt Regular No 1150308. "Santiago 1850: la capital antes de su modernización. La mirada urbana de la expedición naval astronómica norteamericana de J. M. Gilliss". Investigador principal: Germán Hidalgo. Co-investigadores: Rodrigo Booth; Amarí Peliowski; Christian Saavedra; José Rosas; Wren Strabucchi; Catalina Valdés.

Profesor Titular Instituto de Geografía, Pontificia Universidad Católica de Chile. jigonzal@uc.cl

Profesor Titular. Escuela de Arquitectura, Pontificia Universidad Católica de Chile.ghidalgb@uc.cl 
Desde el momento mismo en que se inician los procesos de independencia de los países americanos, las autoridades de gobierno de las nacientes repúblicas vieron la necesidad de conocer, entre otros aspectos, las características del territorio que les correspondería administrar, tanto en sus aspectos naturales como culturales, es decir, los recursos físicos, económicos y humanos. Tanto es así que Sagredo afirma que: "en el Chile de la organización republicana, donde todo estaba por hacerse, y en medio de las tribulaciones políticas y la pobreza del erario, hubo gobernantes que tuvieron plena conciencia de la necesidad de conocer cabal y científicamente el territorio y la realidad nacional. Entonces ni siquiera existían mapas medianamente aceptables; poco y nada se sabía de la situación exacta de las ciudades y puntos geográficos de importancia; nadie había estudiado sistemáticamente las especies naturales y, menos aún, preocupado de las características geológicas o de precisar adecuadamente las condiciones climáticas de los ambientes en que comenzaba a desenvolverse la república" (Sagredo (2), 2010: xv). De hecho, Errázuriz, al comparar la primera etapa de la historia nacional con una segunda iniciada en 1830, en cuanto al reconocimiento geográfico del territorio se refiere, señala que en esta última "correspondiente a los gobiernos de Prieto, Bulnes y Montt, se realizan trabajos fundamentales de reconocimiento del territorio nacional, descripciones y obras cartográficas que manifiestan claramente el interés y preocupación de los gobiernos por conocer, explorar sus riquezas y fijar sus límites" (Errázuriz, 1981: 13) . En atención a lo anterior y dado que los cuadros nacionales eran generalmente escasos para emprender una tarea de esa magnitud, fue necesario recurrir a hombres de ciencias extranjeros para iniciar esta labor de reconocimiento y levantamiento de información, tan necesarios para organizar y gestionar el territorio. Es en este contexto que llegan a nuestro país, entre otros, intelectuales y hombres de ciencia como Andres Bello, Ignacio Domeyko, Rudolfo Philippi, Claudio Gay y Amado Pissis (Sagredo, 2012: 11). El caso de Chile no es ajeno a lo que ocurre en otros países de América, prueba de ello "es la tarea desempeñada por d'Orbigny en Bolivia, como la de Agustín Codazzi en Venezuela y Nueva Granada, Raimondi en Perú y Gay en Chile" (Sagredo (1), 2010: 15). En definitiva, tal era el desconocimiento de las características del territorio nacional en esa época, que el propio Claudio Gay, cuando ofrece sus servicios a las autoridades políticas del país en 1830, señala que eligió Chile "no solamente por la riqueza de su suelo y la variedad de su clima, sino porque es un país desconocido absolutamente por los naturalistas" (Stuardo. 1973: 87).

Por otro lado, en un contexto más global se mantiene y se intensifica el interés de científicos, especialmente de las naciones europeas, por conocer la realidad del continente americano, atraídos tanto por su naturaleza como por sus habitantes, así como también por la potencialidad de sus recursos naturales. No es de extrañar entonces la serie de expediciones científicas que surcan los mares y territorios de América, organizadas por naciones extranjeras que se incrementaron con fuerza durante el siglo XVIII y continúan en el XIX, a las que se añaden otras de carácter individual al estilo de la de Alexander von Humboldt (Sagredo, González, 2004: 75).

Al mismo tiempo, los hombres de ciencia se interesaron por llevar adelante proyectos científicos que permitiesen resolver o actualizar los conocimientos disponibles, muchos de los cuales requerían de análisis comparados o experimentos que se ejecutaran en diversas latitudes del planeta. Naturalmente, junto con el interés científico propiamente tal, existieron también importantes intereses geopolíticos que alentaron a las naciones más desarrolladas a realizar este tipo expediciones, sobre todo visitando aquellos territorios menos conocidos. De tal suerte que, junto con acometer las correspondientes tareas científicas, les fue posible realizar también otro tipo de prospecciones, destinadas a levantar información más general sobre la geografía, las infraestructuras, las ciudades y las gentes de estos nuevos territorios. No debemos olvidar que cuando este 
tipo de proyectos estaban en pleno auge, también era el momento en que los afanes expansionistas y colonizadores estaban más activos (Pratt, 2010). El retiro de España del continente americano, en las primeras décadas del siglo XIX, tras los procesos independentistas, despertó el apetito de las potencias rivales. Un caso especial lo constituían los Estados Unidos; una nación muy joven, que se encontraba todavía en pleno proceso de formación y para la cual debe haber sido de mucho interés conocer lo que estaba ocurriendo en el otro extremo del continente, particularmente, en la costa del Pacífico, donde por cierto se encontraba Chile, y su puerto principal, Valparaíso, que por entonces cumplía un papel hegemónico, como puerta de entrada al continente.

No debemos olvidar que en este contexto, durante el siglo XVIII se ejecutaron importantes proyectos científicos, como aquel que lideró la Academia de Ciencias de París, entre 1735 y 1745, que permitió conocer la verdadera forma y dimensiones de la Tierra, para lo cual fue ineludible efectuar mediciones en las proximidades del polo norte y en las cercanías del Ecuador. En este mismo orden de cosas, se inscribe el hecho que ahora nos ocupa, como es que a mediados del siglo XIX, el matemático alemán Dr. C. L Gerling de la Universidad de Marburgo tenía interés en llevar adelante un proyecto cuyo fin era efectuar un nuevo cálculo para determinar la distancia que separa la Tierra del Sol, mediante la aplicación del método de paralaje solar ${ }^{4}$, sistema que él había perfeccionado, y cuya modificación consistía en que además de hacer observaciones cerca de la oposición del planeta Marte, también se hicieran otras al planeta Venus cercanas a la fase estacionaria, durante su paso por el disco solar, lo que podría entregar mejores resultados de la paralaje (Hidalgo (1), 2017:14). Para ello, era necesario efectuar mediciones en dos lugares lo más distantes posibles, idealmente sobre un mismo meridiano.

Es así como, C. L. Gerling invita al teniente J. M. Gilliss a sumarse a este proyecto. Gilliss propone al gobierno de su país en 1848 realizar una expedición a Chile para observar al planeta Venus cercano a su período estacionario y oposición en 1849. El Congreso de los Estados Unidos aprobó la expedición y otorgó un financiamiento de 5.000 dólares para su realización. Dado que Washington, lugar donde estaba emplazado el observatorio astronómico norteamericano, y Santiago de Chile se ubican en meridianos próximos, la capital de Chile, fue el lugar elegido para realizar las observaciones requeridas ${ }^{5}$. En relación a lo antes señalado es posible imaginar que el interés de Washington por financiar la expedición de Gilliss iba más allá de concretar los objetivos científicos, considerando que era de su utilidad conocer de la mejor manera posible los territorios bajo su influencia política y económica. En este sentido, no deja de sorprender que el primer volumen del informe que preparó Gilliss para dar cuenta del resultado de la tarea encomendada, no haya estado dedicado a exponer los resultados científicos de la misión, sino a explicar y describir detalladamente Chile como Estado y nación. Sorprende también el hecho de que el experimento no se haya concluido de manera exitosa, debido, precisamente, a que el proceso de observación que se debía realizar en Washington no se completó satisfactoriamente (Schrimpf, 2014).

Es el ángulo bajo el que se ve el radio ecuatorial de la Tierra desde el centro del Sol. El método de la paralaje solar, se utiliza para medir la distancia de la Tierra al Sol y consiste en medir desde distintos puntos de la Tierra el tiempo que tarda el planeta Venus en cruzar el disco solar. Por efecto de la perspectiva, dos observadores no ven proyectarse a Venus sobre el mismo punto del Sol, sino que lo ven recorrer cuerdas paralelas próximas, de diferente longitud. El paso dura un tiempo diferente para cada observador. A partir de esa diferencia, es posible hallar la distancia entre las cuerdas en radios solares y el ángulo con que Venus se subtiende a los dos observadores, y calcular así la paralaje solar. En un primer momento se había pensado en Chiloé por la similar latitud de Washington con la Isla, pero dadas las condiciones meteorológicas que reinan en la Isla de Chiloé, se optó por la ciudad de Santiago. 
Luego de permanecer en Chile durante tres años, desde octubre de 1849 y hasta fines de 1852, los miembros de expedición finalizaron sus actividades, las que fueron reseñadas por James Melville Gilliss a través de la publicación realizada entre 1855 y 1895 titulada: "The U.S. Naval Astronomical Expedition to the Southern Hemisphere during the Years 1849-50-51-52" la cual está compuesta por seis volúmenes: I Chile (Gilliss, 1855: 1-660); II Descripción Flora y Fauna y narración viaje guardiamarina Archivald MacRae; III Mediciones astronómicas; IV Catálogo de estrellas observadas; V Catálogo de estrellas observadas y VI Observaciones magnéticas y meteorológicas. Parte importante de este documento, es la serie de planos y mapas geográficos sobre Chile que ilustran la información contenida en él, las cuales, en su mayor parte, están basadas en el trabajo que realizaban hombres de ciencias radicados en el país, con los cuales el teniente Gilliss estableció relaciones académicas y profesionales.

Entre otras consideraciones, algunos de los beneficios que trajo para el país esta expedición científica fue que la publicación de Gilliss tuvo la virtud de reunir en un extenso documento su visión sobre la situación política, económica y social del Chile de mediados del siglo XIX y, por otra, colaboró en el origen de la astronomía de nuestro país, al facilitar la adquisición de las instalaciones e instrumental del observatorio astronómico norteamericano que el gobierno chileno compró durante la administración de Manuel Montt.

La expedición también tuvo el valor de congregar y publicar un conjunto de cartografías, algunas de ellas inéditas, de distintos autores como Claudio Gay y Amado Pissis que, en aquella épo$\mathrm{ca}$, se encontraban preparando la cartografía nacional. Lo realmente novedoso es que el material cartográfico fue complementado con vistas de un real valor como representaciones por su alto grado de verosimilitud, en una época en que la fotografía recién comenzaba a estar disponible para retratar espacios abiertos. Así, con esta mezcla virtuosa de cartografía y vistas topográficas, reunidas en el afán de describir para dar identidad al territorio nacional, se dotó a Chile de un instrumento de conocimiento y de difusión de su realidad material de un gran nivel científico (Hidalgo (2), 2017: 5 y 11).

En efecto, la expedición astronómica perpetró algo que otros viajeros también habían realizado, pero con un instrumental y una experticia nueva para Chile. Lo que Chile incorporó, en resumidas cuentas, fue un registro ejecutado bajo una nueva forma de ver la realidad, actualizada, y en muchos aspectos moderna (Hidalgo (2), 2017: 4-5).

Por otra parte, conviene tener presente que la ciencia cartográfica a mediados del siglo XIX, había hecho notables progresos, tanto teóricos como aplicados, en especial la cartografía topográfica, producto del trabajo que venía realizando desde el siglo XVIII la familia Cassini en Francia, cuyo modelo de representación fue seguido por la mayor parte de las naciones occidentales. Tanto Claudio Gay como Amado Pissis, formados en Francia, eran conocedores de estos avances, por lo cual, en sus trabajos en Chile, pusieron en práctica estos nuevos conocimientos y adelantos. Para ello era indispensable contar con el instrumental adecuado, para efectuar los levantamientos cartográficos con base astronómica o geodésica. La utilización de estos nuevos instrumentos, así como la aplicación de técnicas en uso para representar la planimetría y altimetría, les permitió a Gay y Pissis, lograr buenos niveles de precisión en sus mapas. En virtud de lo anterior, las imágenes cartográficas que acompañan el texto de Gilliss, basados en ellos, más sus propias contribuciones, son dignas de relevarlas y darlas a conocer. 


\section{La cartografía en el documento de la expedición}

El documento elaborado por la Expedición Astronómica Naval de los Estados Unidos, destinó el volumen I publicado en el año 1855, denominado Chile, a describir las características geográficas, económicas, políticas y sociales que presentaba nuestro país a mediados del siglo XIX. Su primera sección está formada por quince capítulos: descripción geográfica; divisiones políticas y distribución de recursos industriales; el clima; terremotos; el gobierno; la sociedad; la iglesia y sus ceremonias; Santiago; Valparaíso; visita a las provincias de Atacama y Coquimbo; aguas termales; la elección presidencial de 1851; acontecimientos que se sucedieron a la elección; una visita al país y una visita al sur. Dicho texto está acompañado por un conjunto de planos y mapas geográficos, formado por un mapa general de Chile; un plano de la ciudad de Santiago; un plano de la ciudad de Valparaíso; un plano de Constitución y del puerto en la boca del río Maule y un mapa de la provincia de Santiago 6 .

Para la confección del documento relacionado con las características geográficas del territorio chileno, así como para la elaboración de las piezas cartográficas, el teniente J. M. Gilliss se valió de sus propios viajes de reconocimiento, pero fundamentalmente de los escritos realizados por una serie de científicos y profesionales que se encontraban trabajando en Chile al momento del arribo de la expedición, destacando entre ellos a Claudio Gay, Amado Pissis, Allan Campbell, William Wheelwright, Ignacio Domeyko, Rudolfo Amando Philippi y Andrés Bello.

Figura № 1. Mapa General de la República de Chile que forma parte del documento de Gilliss, se representa el territorio de Chile en tres hojas independientes.

Mapa General de la República de Chile.
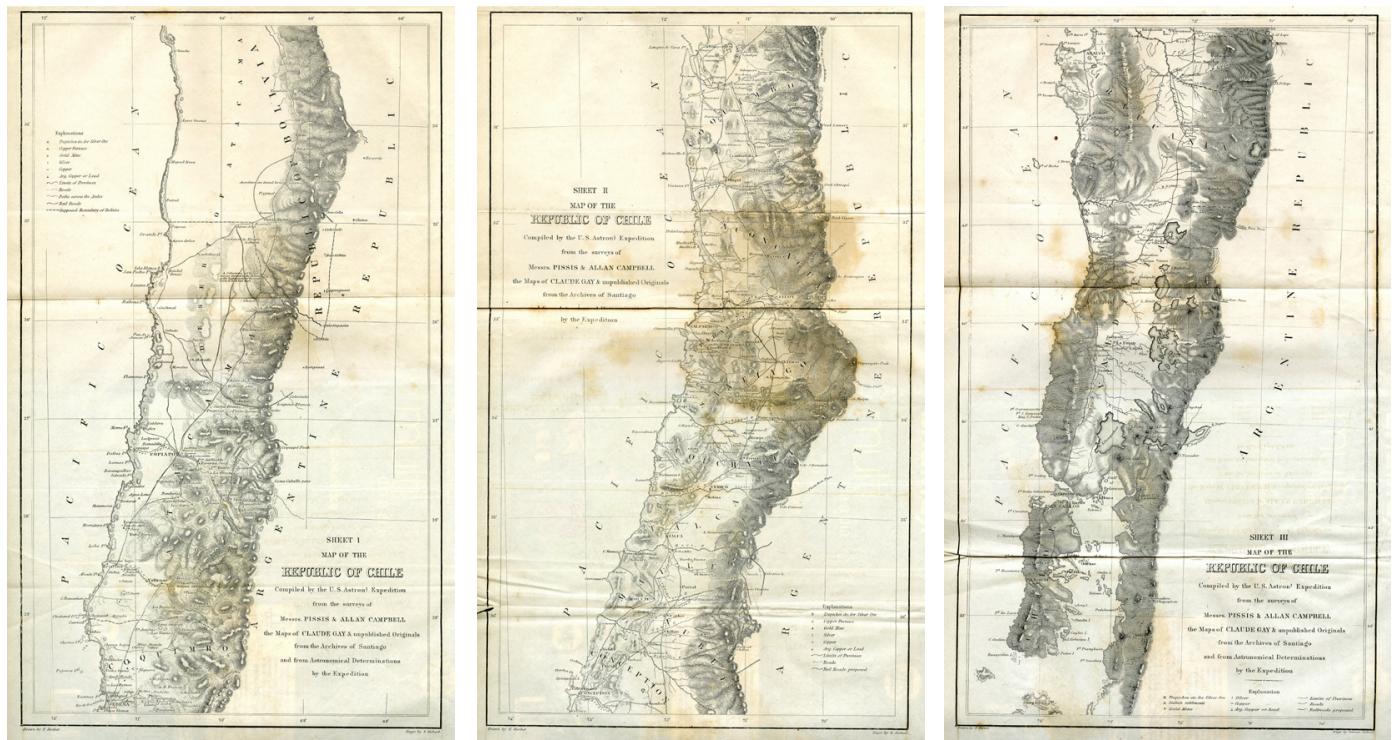

El documento elaborado por la expedición naval astronómica de los Estados Unidos en Chile, tuvo entre otros méritos, el ser muy bien ponderado por el humanista alemán Alexander von Humboldt, quien se vale de la información contenida en el texto y lo cita, cuando trata la hipsometría de los volcanes, junto a otros científicos que trabajaron en Chile, en su magna obra Cosmos, publicada en alemán entre los años 1845 y 1862. 
El mapa de Chile General (Figura No 1), está compuesto de tres secciones; norte, centro y sur. Cada una de ellas abarca una extensión de $7^{\circ}$ en latitud y, cubre en su conjunto el territorio chileno comprendido entre los $23^{\circ}$ y los $44^{\circ}$ de latitud sur. Está confeccionado sobre una proyección equivalente, a una escala de 1: 3.000.000, aproximadamente. Presenta el trazado de paralelos y meridianos cada un grado, tanto en latitud como en longitud. Su meridiano cero u origen es el de Greenwich, asunto que lo diferencia claramente del mapa en que se basó para su confección, como lo es el mapa general de Chile de Claudio Gay, quien utilizó el meridiano de Cádiz para ello, modificación que significó un ajuste de esta coordenada geográfica, como línea de referencia para la determinación de la longitud'; otra innovación de importancia es la que se aprecia en el diseño del mapa, respecto del original, ya que Gay representó el territorio de Chile en toda su extensión longitudinal, en una sola lámina y, no en tres como Gilliss. Con todo, a pesar de estas transformaciones, no se trata de un levantamiento original sino que corresponde a un mapa compilado, basado como se ha dicho de manera preferente, en la cartografía inédita de Claudio Gay que éste había dejado en Chile antes de viajar a Francia en 1842, para supervigilar la publicación del Atlas de la Historia Física y Política de Chile; de igual modo se apoyó, en el levantamiento que estaba realizando Amado Pissis, desde 1848, en cumplimiento con lo solicitado por el gobierno, para disponer de un Plano topográfico y geológico de la República de Chile; también utilizó los trabajos de geomensura realizados por el ingeniero Allan Campbell, quien tenía a su cargo el proyecto del trazado del ferrocarril de Santiago-Valparaíso. Todo lo cual queda debidamente reconocido, por parte de su autor, en los créditos de cada una de las hojas del mapa. Sin embargo, cabe destacar, que los miembros de la expedición también habían realizado sus propias mediciones astronómicas, en el cumplimiento de los objetivos que la expedición se había propuesto para su estadía en Chile, por lo que el mapa contiene significativas mejoras en la localización geográfica de diversos lugares y accidentes geográficos, en especial de Santiago y su entorno.

El mapa en referencia, se vale de símbolos lineales, puntuales y areales, expresados en la leyenda del mapa, para representar los diversos hechos y fenómenos de carácter planimétricos del territorio, como son los caminos, límites administrativos, centros poblados, yacimientos mineros, incluso un asunto de interés de ese momento; el trazado de un proyecto de ferrocarril entre Santiago y Valparaíso. Por su parte, para representar los elementos altimétricos, como era frecuente en esa época, la simbología empleada es de carácter convencional, de ahí que para mostrar el relieve, utiliza el método de las normales de pendiente para los sectores más escarpados y, el de las normales simplificadas, del tipo de oruga o rama de pino, para las áreas con menor pendiente. Su toponimia, está orientada de manera preferente para identificar los diferentes fenómenos, tanto naturales como culturales, recurriendo para ello a distintos tipos y tamaños de letras, como ocurre, por ejemplo, con la identificación de cada una de las provincias en las que se encontraba dividido el país a mediados del siglo XIX, la individualización de las principales ciudades y centros poblados, así como también para los ríos, lagos, islas, volcanes, etc.

En definitiva, el mapa presenta notables cualidades de una buena representación cartográfica, acorde con las normas de uso común entre los cartógrafos de la época, entre las cuales podemos destacar en este caso: su expresión, legibilidad y eficacia. ${ }^{8}$

El meridiano de Greenwich fue adoptado, por acuerdo internacional, recién en 1884 como meridiano de referencia universal.

\& Para Joly, en cartografía se reconoce como cualidades de un buen mapa: la precisión, asociada a la proyección y su escala; la expresión, vinculada con el arte de resaltar lo más importante por sobre lo secundario; la legibilidad, relacionada con la facilidad para descodificar la información, a través de su simbología; la eficacia, con el cumplimiento del objetivo del mapa, a las que se le añade, la leyenda y el título, elementos indispensables de un mapa. En: Joly, Fernand, La Cartografía, págs. 106-112. 
Figura $N^{\circ}$ 2. Plano de la ciudad de Santiago, levantado por oficiales de la Academia Militar de Santiago. En su leyenda se identifican una serie de puntos de interés de la ciudad, entre otros el cerro Santa Lucia, lugar donde se localizó el Observatorio Astronómico de la expedición. Plano de la ciudad de Santiago.

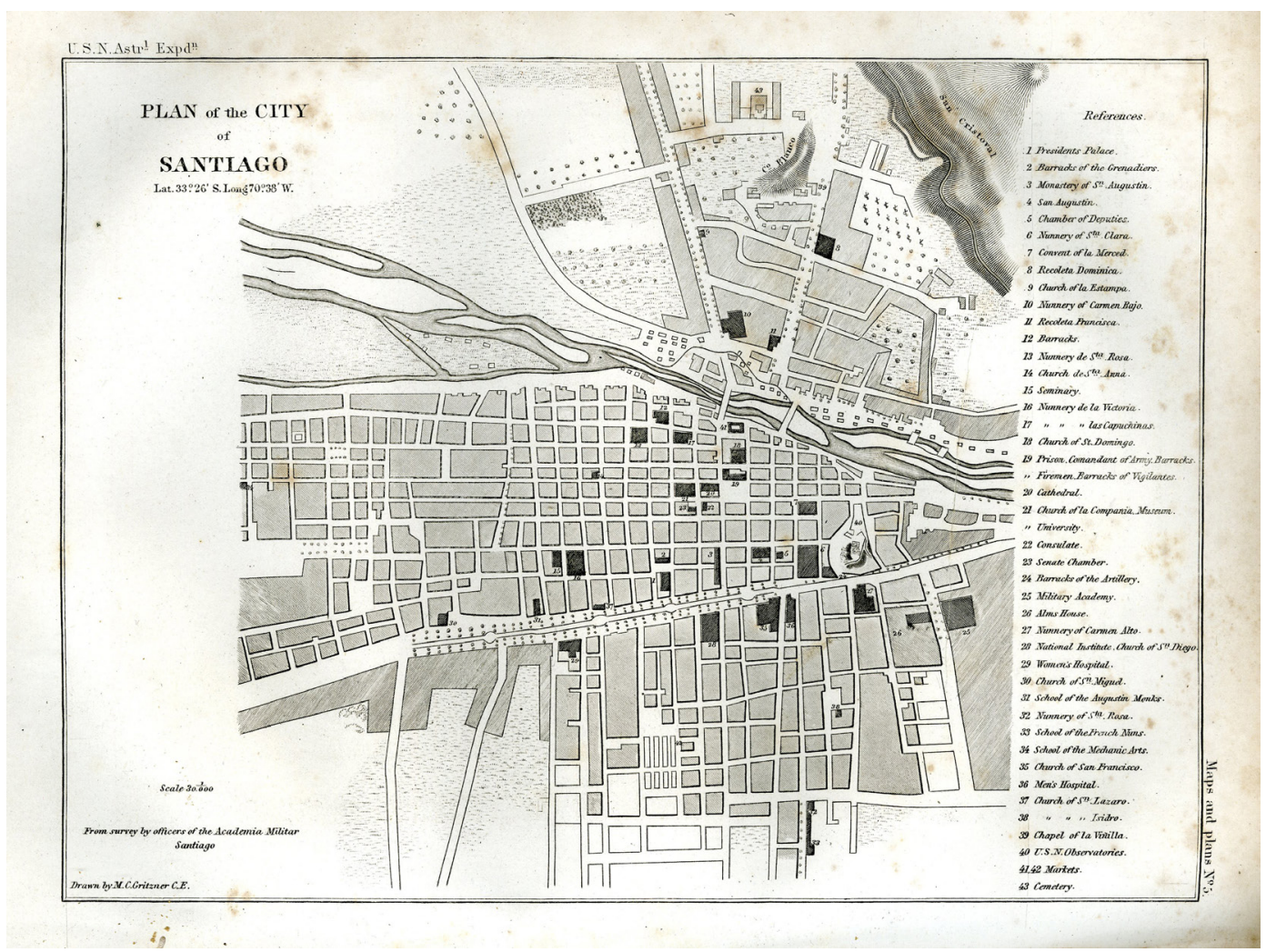

El plano de la ciudad de Santiago (Figura $N^{\circ} 2$ ), inserto en el documento de Gilliss, está confeccionado a escala 1: 30.000. Corresponde a un levantamiento original realizado por los oficiales de la Academia Militar de Santiago, tal como lo señala la fuente del plano ${ }^{9}$, y dibujado por Max C. Gritzner C. E, en Washington D.C. Tiene como referencia las coordenadas geográficas del Cerro Santa Lucía: $33^{\circ} 26^{\prime}$ de Latitud Sur y los $70^{\circ} 38^{\prime}$ de Longitud Oeste. Como en toda la cartografía de Gilliss, se utiliza el meridiano de Greenwich como referencia de la longitud geográfica. En su leyenda, se señalan con un número 43 elementos que se ubican en el plano, los que corresponden entre otros, a instituciones como iglesias, conventos, hospitales. Aunque no se indica explícitamente, es posible identificar algunos sectores de viñedos y campos de cultivos, en el área norte y sur de la ciudad, también se sitúan los cerros Santa Lucía, Blanco y el San Cristóbal.

Sin duda alguna, el plano fue concebido para mostrar la ubicación de las instituciones que la expedición juzgó más importantes de la capital. Su esquematismo de la forma urbana como de

\footnotetext{
9 Entre los miembros del Cuerpo de Ingenieros del año 1847, se encontraban los tenientes Alberto Blest Gana, Luis Arteaga, Juan A. Donoso, Cesar Lazaeta y Nicanor Gana. Estos antecedentes fueron aportados por el historiador militar, don Pedro Eduardo Hormazábal Espinoza, quien preparó un breve compilado de la Información existente sobre el tema, bajo el título: Información obtenida desde Antecedentes de Memoria de Guerra.
} 
la situación geográfica de sus elementos, corrobora esta apreciación. Por lo mismo, su valor se encuentra en la identificación y localización de las instituciones, las cuales se listan en la leyenda que acompaña al plano, de un modo sistemático y sensible (Hidalgo (2), 2017: 8-9). En efecto, el análisis del listado revela una comprensión bastante profunda de la estructura de la ciudad y su organización, al agrupar las instituciones de acuerdo a su relación con los elementos que ordenan el territorio: El río Mapocho y el paseo de la Alameda de las Delicias, además del principal espacio público de la ciudad: la Plaza.

Es importante señalar que desde los inicios de la república, la ciudad de Santiago fue objeto de diversos levantamientos cartográficos, algunos de estos planos fueron trazados con bastante precisión y otros tuvieron un carácter más esquemático. El plano de la expedición se sitúa en un momento bastante singular de la historia de la cartografía de la capital (Martínez, 2007: 60-61). Se trata del momento en que aún no se disponía de registros precisos de la ciudad, el mejor de todos ellos era el de Claudio Gay, que se publicó en Francia en 1831, y cuando, por otro lado, la ciudad comenzaba a extenderse más allá de los límites naturales y geográficos que la habían mantenido retenida en su crecimiento, prácticamente, desde su fundación. Como se ha señalado, la forma en que la ciudad comenzó a expandirse, contrariamente a lo que se pensaba, fue a través de un conjunto de núcleos dispersos, situados mucho más allá de las barreras geográficas que la confinaron por siglos: el río Mapocho, el cerro Santa Lucía, La Cañada y el canal de Negrete, y no como una mancha homogénea que se expandió desde su núcleo central (Hidalgo, Rosas y Strabucchi, (3) 2017: 116-117). En este sentido, el plano de Santiago publicado por Gilliss tiene el mérito de destacar que, en torno a 1850, Santiago efectivamente se encontraba en un período de expansión, pero como lo señalan otras fuentes, a su vez yerra al representar la ciudad como entidad continua y homogénea, que se expande desde el centro a la periferia (Rosas, Strabucchi, Hidalgo, González, 2017: 21), como lo advirtió Leonardo Espinoza cuando señaló que el plano de Gilliss deja en "evidencia la decidida expansión de la ciudad en los terrenos recientemente parcelados de la quinta Portales (al poniente de la actual Av. Brasil)" (Espinoza, 2008: 66), juicio en cierta forma correcto, pero no preciso, pues no contempla el orden en que se sucedieron los hechos. Tampoco es correcto el trazado geométrico del plano, que olvidó la regularidad geométrica de las manzanas del casco fundacional. En efecto, algunas de las manzanas en torno a la Plaza se dibujaron con forma rectangular y en los cerros no hubo una representación cuidada ni de su silueta ni de su tridimensionalidad, lo que confirma que el verdadero interés no estaba en realizar una cartografía con rigor geométrico, sino más bien mostrar las relaciones que se establecen al interior de la ciudad entre elementos estructurales a escala geográfica y los elementos puntuales pero significativos. Con ello, el plano pone en valor la leyenda, y demuestra que, más allá de su mera función enunciativa, puede ser motivo de reflexión y quedar cargada de intencionalidad.

El mapa de la Provincia de Santiago (Figura $N^{\circ} 3$ ), incorporado en el documento de la expedición, es sin duda el más novedoso y destacado dentro del conjunto cartográfico, por su primicia al publicarse en 1855, antes del que le sirvió de base y por los atributos cartográficos que le incorpora Gillis. En efecto, no es un levantamiento cartográfico original de la expedición, sino que se elaboró a partir, según lo consigna Greve, del realizado por Amado Pissis a inició del mes de octubre de 1848 (Greve, 1946: 42). Dicha autoría es corroborada por Gilliss en su texto cuando señala que: "en el transcurso de una inspección trigonométrica para el gobierno, el señor Pissis exploró desde la latitud $32^{\circ} 20^{\prime}$ hasta la latitud $34^{\circ}$; hacia el este llegó hasta la cresta más alta. Amistosamente, me proporcionó una copia pequeña de su mapa" (Gilliss, 2017: 38). Sin embargo, el mapa de la provincia de Santiago del documento, comprende sólo el área de dicha provincia, 
enmarcada entre los $32^{\circ} 54^{\prime}$ y los $34^{\circ} 26^{\prime}$ de latitud sur, cuya superficie fue estimada por Gilliss en 14.923 millas cuadradas. Sus límites estaban definidos por: al norte, el cordón de Chacabuco y las altas cumbres de los cerros hasta la línea de la costa; al sur, el curso del río Cachapoal y su continuidad en el río Rapel; al este, la cordillera de Los Andes; y al oeste, el océano Pacifico ${ }^{10}$. Las coordenadas geográficas del mapa fueron representadas por el trazado de paralelos y meridianos cada 30' en latitud y longitud. Fue confeccionado sobre una proyección equivalente a una escala 1: 300.000, aproximadamente. La representación de la altimetría, que es de carácter convencional, utiliza el método de las normales de pendiente para mostrar el relieve y las cotas de altitudes están expresadas en pies. Por su parte, para la planimetría se hizo uso de símbolos puntuales, lineales y areales, cuando fue necesario representar ciudades, pueblos y aldeas; caminos, ríos y lagunas, respectivamente. La toponimia del mapa, está orientada esencialmente a la identificación de las ciudades y pueblos, ríos, esteros, lagunas, cerros, volcanes, etc.

Figura $N^{\circ}$ 3. Mapa de la Provincia de Santiago, incluido en el documento de la expedición. Confeccionado sobre la base de un mapa original, e inédito, de las provincias de Santiago y Valparaíso, de Amado Pissis del año 1850.

Mapa de la Provincia de Santiago.

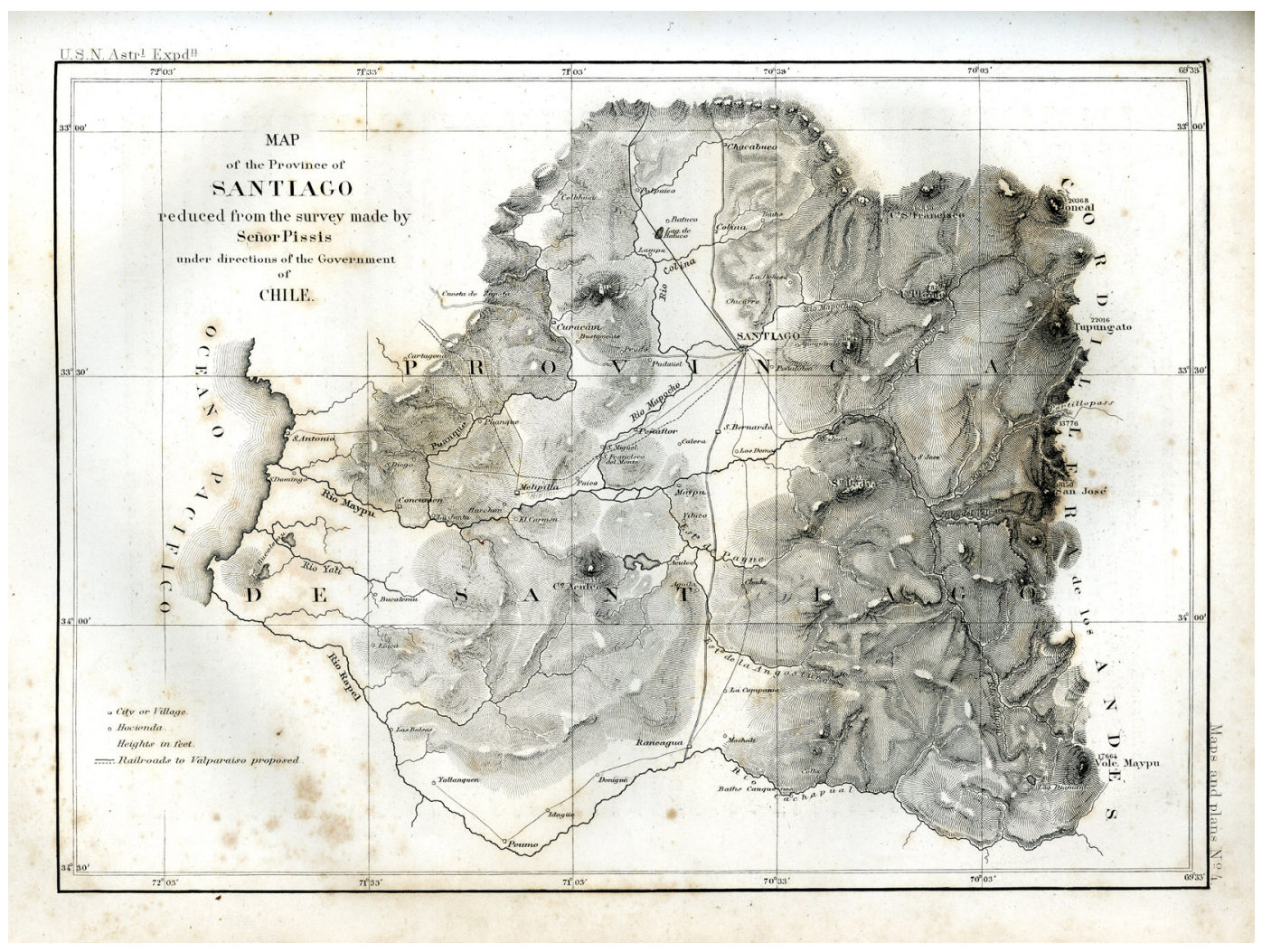

10 Límite de la Provincia de Santiago, vigente desde la creación de la Provincia de Valparaíso en 1842. Ley del 27/10/1842. 
Sin embargo, es importante considerar que para comprender la vinculación que existe entre el mapa de la provincia de Santiago de la Expedición Astronómica, y la información proporcionada por Pissis para la elaboración de dicho mapa, es necesario tener en cuenta que ya, en 1850, Amado Pissis entregó los primitivos planos originales de la provincia de Santiago, los que completó más tarde - 1858 y 1859 - con el agregado de nuevos caminos, vías férreas y poblaciones, pasando después a denominarse Santiago $N^{\circ} 1$ en el respetivo original a escala 1: 250.000 (Greve, 1946: 89). Posteriormente, esta hoja en el atlas de Pissis, publicado en 1873, comprende la provincia de Santiago y parte de la provincia de Valparaíso (Figura $\mathrm{N}^{\circ} 4$ ), dado que los editores tomaron la decisión de no grabar cada provincia del país de manera independiente, sino que en hojas de 50 $\mathrm{cm}$. de largo por $90 \mathrm{~cm}$. de ancho, para permitir así su acoplamiento (Greve, 1946: 84). Con todo, sabemos hoy de la existencia previa de un mapa de la provincia de Santiago de Pissis, grabado en piedra el año 1857, por el litógrafo Narciso Desmadryl en la ciudad de Edimburgo, Gran Bretaña, en la Casa Adán y Carlos Black. Pissis puntualiza que, "el meridiano principal, que es el mismo que sirve de punto de partida para contar las longitudes, es el del observatorio que había sido establecido sobre el cerro Sta. Lucia y cuyas coordenadas eran: longitud $72^{\circ} 58^{\prime} 32^{\prime \prime}$ al oeste del meridiano del Observatorio de París" (Greve, 1946: 78-79).

Figura $N^{\circ} 4$. Mapa de la Provincia de Santiago y parte de la de Valparaíso a escala 1: 250.000. Publicado en 1873 por Amado Pissis, como parte del Plano Topográfico y Geológico de la República de Chile.

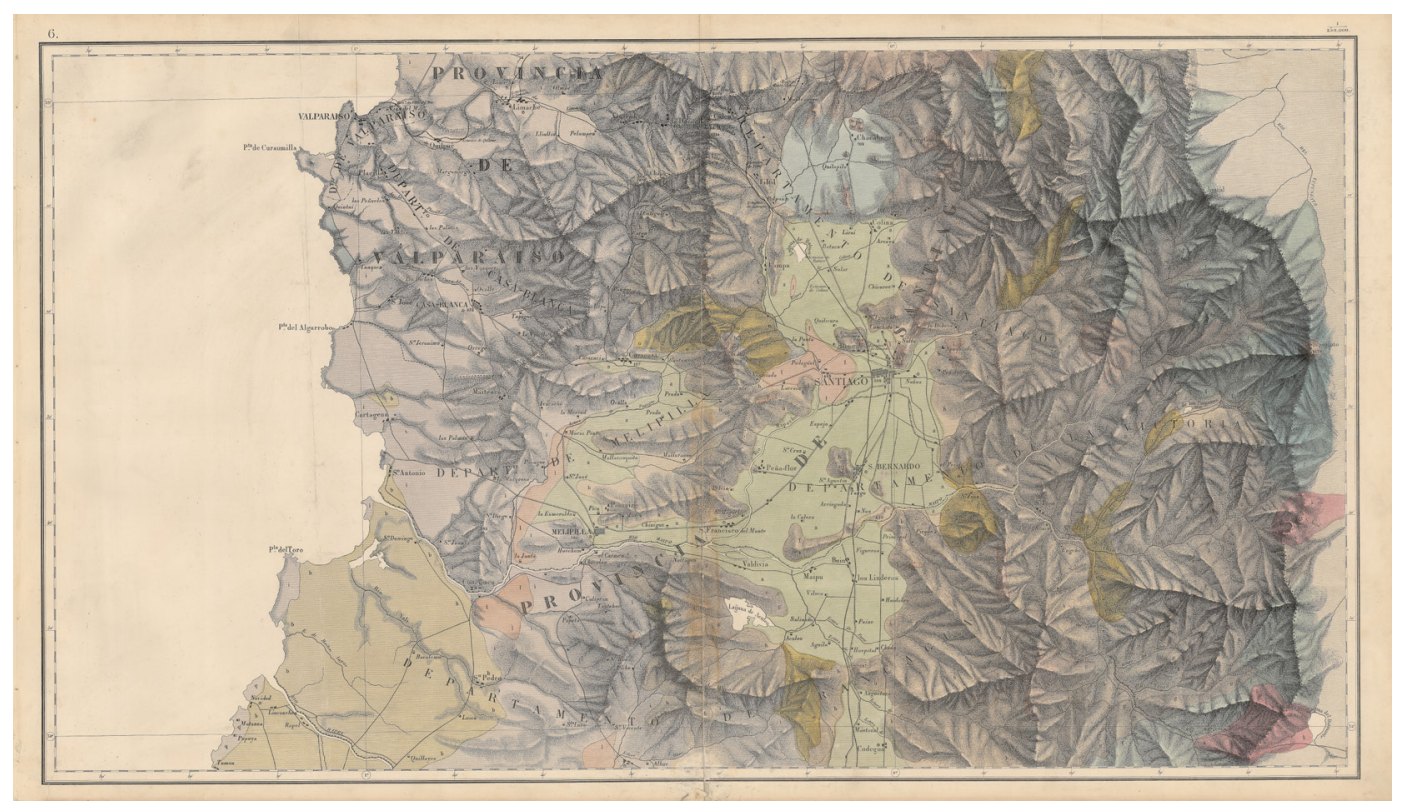

En virtud de los antecedentes dados a conocer previamente, hay razones fundadas para afirmar con certeza que Gilliss utilizó los planos originales de la provincia de Santiago de Pissis del año 1850, para confeccionar el suyo. Dos asuntos de interés llaman la atención del mapa de Gilliss de la Provincia de Santiago. Por una parte, el meridiano cero u origen del mapa, como es habitual en su cartografía, está referido a Greenwich. Sin embargo, la numeración de los meridianos no se indicó con números enteros para mostrar la separación entre ellos, como es usual, aunque sí mantienen su progresión cada 30'. De este modo, el meridiano que pasa por las inmediaciones de 
la ciudad de Santiago, se señaló como $70^{\circ} 33^{\prime}$ y no como $70^{\circ} 30^{\prime}$ que hubiera sido lo corriente; lo anterior tiene presumiblemente su explicación en el hecho que Gilliss quiso georreferenciar su mapa, con el meridiano que pasa por el Observatorio Naval Astronómico de Washington, cuya coordenada es $77^{\circ} 03^{\prime}$. El otro asunto de interés, tiene que ver con la relevancia de la información proporcionada y la actualidad del mapa en el momento de su confección, como lo es el hecho que haya representado la propuesta del trazado que tendría el futuro ferrocarril que uniría las ciudades de Santiago y Valparaíso"1 asunto que, como veremos, en sí mismo, abrirá una faceta en la comprensión de la ciudad de Santiago y su territorio.

Entre las cualidades que presenta el mapa de provincia de Santiago de Gilliss destacan, en especial, su expresión, legibilidad y eficacia, a tal punto que Ignacio Domeyko, con ocasión de escribir su critico artículo sobre el documento de la expedición, hace referencia a éste mapa para ponderar y destacar su valor, así como también para fundamentar sus observaciones, como la anchura que Gilliss le asigna a la cordillera de Los Andes, al decir que: "basta echar la vista sobre la copia del precioso mapa del señor Pissis que acompaña al primer volumen de esta obra, para ver que los Andes propiamente dichos no alcanzar a ocupar la mitad de la anchura del territorio de la provincia de Santiago" (Domeyko, 1857: 637).

Figura $N^{\circ}$ 5. Detalle del mapa de la Provincia de Santiago, elaborado por J. M. Gilliss en el que se observa la representación de la ciudad de Santiago, principal centro urbano, mediante cinco rectángulos yuxtapuestos, a partir de los cuales se proyectan los diferentes elementos que la conectan con los otros centros secundarios.

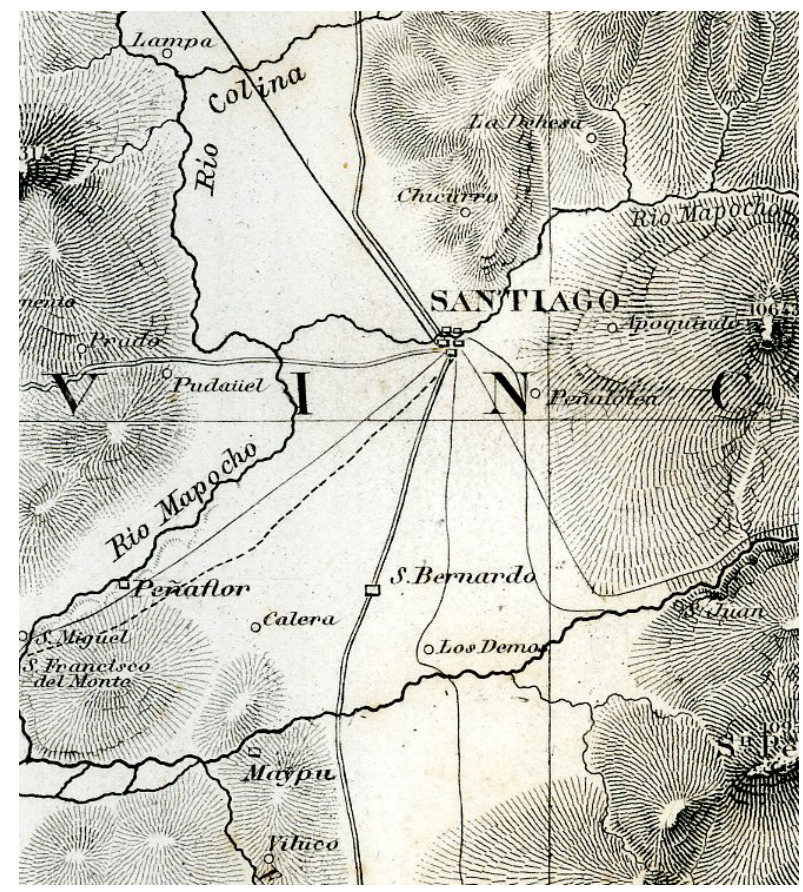

En el mapa se indica el trazado que une ambas ciudades pasando por las cercanías de las localidades de Peñaflor, Paico, Melipilla y Puange. Tres proposiciones se habían estudiado para el trazado del ferrocarril: una por Casablanca y Melipilla; otra por Aconcagua, que pasando por el portezuelo de Montenegro caía al valle y seguía por la costa hasta el Alto del Puerto y la tercera, por las cuestas de Prado y Zapata. En: Ferrocarriles y ramales en Chile. Ferrocarriles del Estado II. Disponible en internet. Consultado el 12 de enero de 2017. 
Coincidiendo con Manuel de Sola-Morales, para quien "la cartografía adquirió su momento más teórico, cuando plantas de continentes o de ciudades, más que describir la realidad la definían, [siendo] capaces de inventar y proponer el universo en el acto mismo de reproducirlo" (Sola-Morales 1980: 2), la realidad que describe el mapa de la Provincia de Santiago, en concordancia con el tipo de pensamiento que la ha producido, se constituiría también en una creación (Figura $N^{\circ} 5$ ). En efecto, no se trata ya de representar la pura naturaleza que envuelve a una ciudad, sino de mostrar cómo la naturaleza se transforma cuando la ciudad comienza a modernizarse, a través de la prolongación de viejos callejones que han devenido en caminos, o con la aparición de una nueva red de canales que proveen el agua que se requiere para su subsistencia y futuro desarrollo. Esta forma de entender el mapa se confirma cuando advertimos que se ha incorporado el trazado del ferrocarril a Valparaíso, que aún se encontraba en estado de proyecto. Sin duda, detrás de esta decisión visionaria, se encuentra el deseo de mostrar ese territorio del modo más actualizado posible, arriesgo de incorporar incluso el trazado de lo que todavía es un posible proyecto. Pero, de un proyecto en específico: el ferrocarril, con todo su despliegue técnico y científico, que irrumpe en la realidad y la resignifica. El mapa no representa ya la naturaleza como hecho dado, acentuando sus contenidos simbólicos y sagrados, sino una nueva naturaleza, fruto de la abstracción que caracteriza al entendimiento humano (Barthes 2009: 61).

Fig. № 6. Plano de Valparaíso, fechado en 1851, expone en todo su esplendor la bahía y la planta urbana de la ciudad. Destaca el método para representar el relieve, que permite resaltar las quebradas y los innumerables cerros que conforman la zona plana de la ciudad.

Plano de la ciudad de Valparaíso.

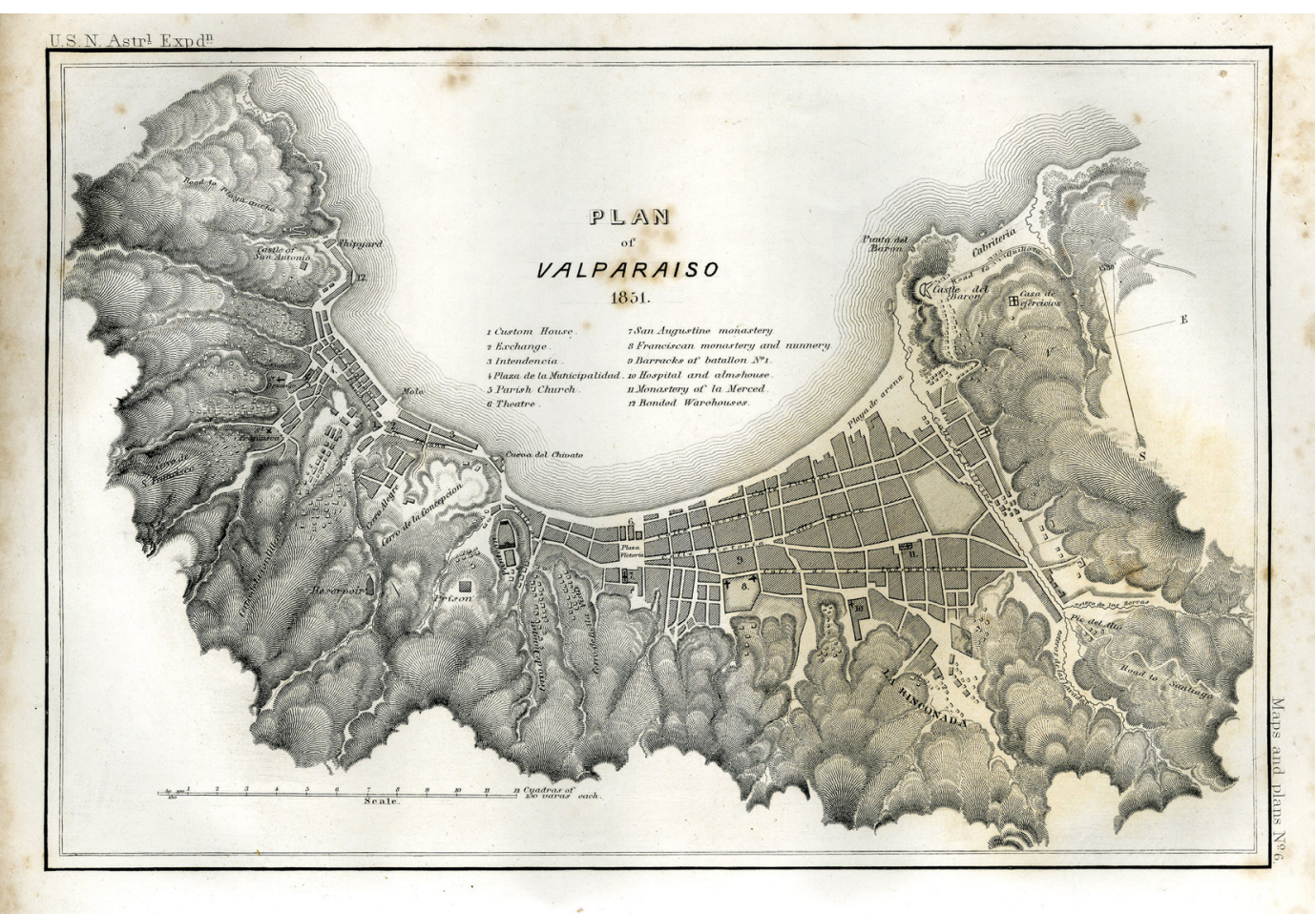

El Plano de Valparaíso (Figura $N^{\circ}$ 6) que forma parte del texto de la expedición, llama la atención por la calidad de su representación cartográfica, en cuanto a su precisión, expresión, le- 
gibilidad y eficacia. Sin embargo, dado que no está firmado ni tampoco se hace referencia al autor de dicho plano en el documento de Gilliss, es posible suponer que fue tomado de algún levantamiento cartográfico coetáneo a la presencia de la expedición astronómica en Chile. En este contexto, surge como una referencia posible el plano de la ciudad y puerto de Valparaíso, que publicó el ingeniero Gustavo Scherff en 1852, con el que hay evidentes similitudes en cuanto a su diseño en la extensión de la línea de costa del plano, trazado de planta urbana de la ciudad, topografía, toponimia, entre otros asuntos, aunque hay que hacer notar que el plano en el texto de Gilliss está fechado en 1851. Cuando Gilliss abordó el tema de las bahías y puertos, en el capítulo correspondiente a la Descripción Geográfica de su documento, dice con respecto al puerto de Valparaíso: "todo escritor en Chile tiene algo que decir de su puerto. Ubicado en la latitud $33^{\circ} 2^{\prime}$, el plano preciso que aparece en el $N^{\circ} 6$ de Mapas y Planos hace innecesario decir aquí más que unas pocas palabras" (Gillis, 2017: 63). Con todo, el plano en referencia no registra información batimétrica de la bahía por lo que cabría de suponer que no fue levantado por marinos, lo que refuerza entonces su cercanía con el plano del ingeniero Scherff. Notoriamente, su autor privilegió mostrar la planta de la ciudad y los cerros que circundan su emplazamiento, así como también las profundas quebradas que separan un cerro de otro. En ello hay una clara intención de representar la configuración espacial de la ciudad, distinguiendo claramente llenos de vacíos, lo artificial de lo natural; es decir, primó la intención de representar un cierto carácter urbano, consistente en la ocupación de la zona plana con un relleno homogéneo, presumiblemente, destinado a uso institucional y residencial, mientras que en las cumbres de los cerros se destaca la implantación de edificaciones con programas arquitectónicos singulares, como: el cementerio, la cárcel, la casa de ejercicios, etc., con excepción de una pequeña urbanización que se emplaza en el Cerro Alegre. En síntesis, el plano intenta ofrecer una idea de ciudad, que debe comprenderse desde el orden propuesto por estas instituciones y accidentes geográficos.

Figura $N^{\circ}$ 7. Detalle de la leyenda del Plano de Valparaíso inserto en el informe de Gilliss. Su autor privilegia localizar las principales instituciones y centros de interés de la planta urbana de la ciudad.

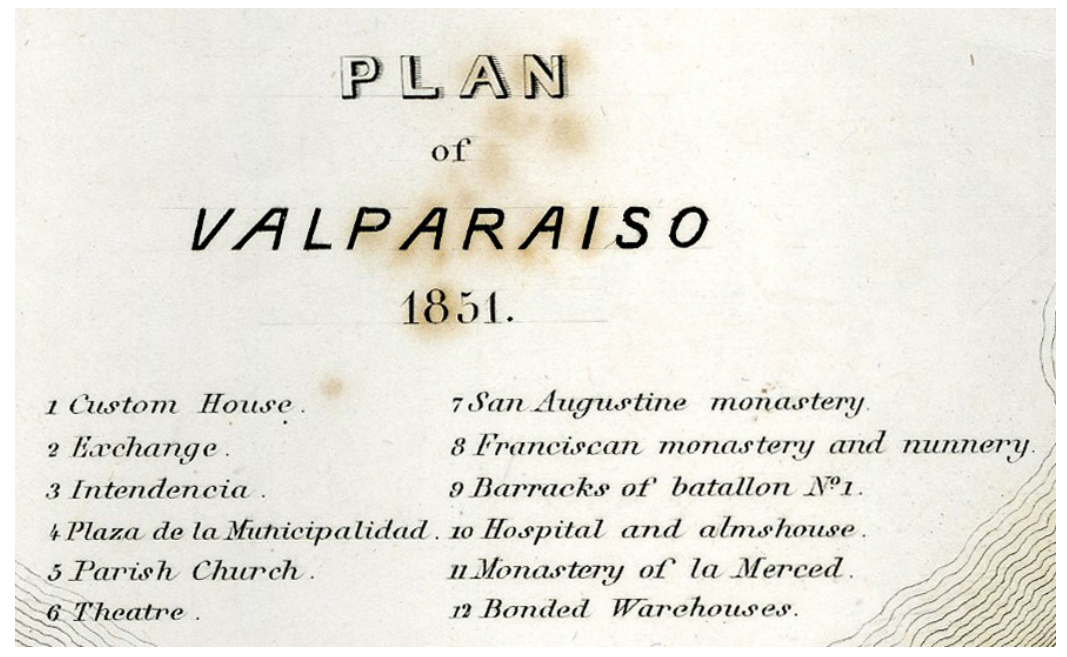

En este contexto, en la leyenda del plano (Figura $N^{\circ} 7$ ), se identifican doce lugares muy bien seleccionados y de indudable interés, todos ellos ubicados precisamente en la parte plana de la ciudad, como los monasterios, hospital, regimiento, plaza, teatro, municipalidad entre otros, los 
cuales se numeran. Distinto es el caso de los elementos situados en los cerros. Éstos últimos, quedan asociados así a las cualidades topográficas del lugar. Con ello se repite, en parte, la misma estrategia cartográfica utilizada en el plano de Santiago, que pone énfasis en la leyenda y la intención de entender la ciudad por medio de la identificación de sus principales instituciones.

En este mismo sentido, la toponimia, se utiliza para identificar algunos lugares de interés de la ciudad, como el nombre de los múltiples cerros, entre otros Cerro Alegre, Concepción, Cordillera. El plano está confeccionado a una escala 1: 10.000 aproximadamente y en su escala gráfica, ubicada al pie del plano se señala que las cuadras son de 150 varas cada una, es decir, de 125 metros. Una última palabra en relación al encuadre que propone este plano, en el cual se cuidó de enmarcar lo urbano, dejando muy claramente señalado los puntos de inicio y fin de la ciudad, y su asociación con la bahía y la secuencia de cerros que se definen y encierran, remarcando además la orientación del conjunto, con el norte hacia arriba, hacía el Océano Pacífico.

Figura Nº 8. Plano de Constitución y Puerto en la Boca del Río Maule, confeccionado al estilo de la cartografía náutica con indicaciones sobre la batimetría, banco estuarial (lateral), espiga litoral, línea de la costa e indicación del norte geográfico o verdadero y el norte magnético.

Plano de Constitución y Puerto en la Boca del Río Maule.

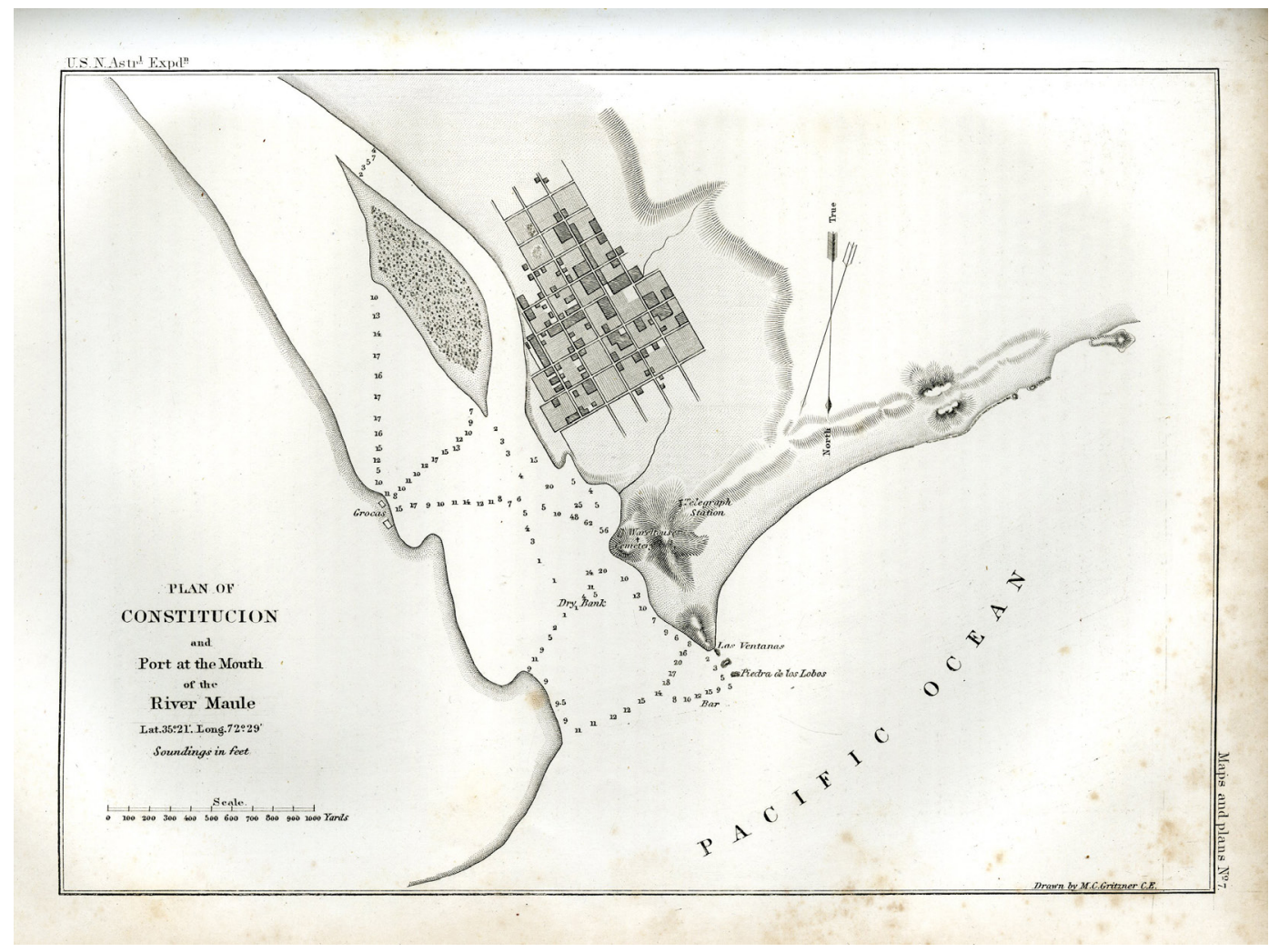

El plano de Constitución y su puerto en la boca del río Maule (Figura $N^{\circ} 8$ ), es bastante esquemático y no está fundado sobre una proyección cartográfica específica, como es habitual en este tipo de planos náuticos, fue dibujado por Max C. Gritzner C.E. Aunque no indica su fuente, presenta similitudes con un plano anónimo titulado Plano de la Villa y Puerto de Constitución del 
año $1853^{12}$, coetáneo a la estadía de la expedición en Chile, no sólo en sus aspectos náuticos sino que también en el diseño de la planta física de la ciudad.

La localización del lugar está dada por sus coordenadas geográficas correspondientes a los $35^{\circ} 21^{\prime}$ de latitud sur y $72^{\circ} 29^{\prime}$ de longitud oeste. Su escala está en yardas y equivale a un plano 1: 20.000 aproximadamente. Su confección se rige por el patrón impuesto por la cartografía náutica o marina, utilizada para la representación de puertos y bahías donde se privilegia el diseño de la línea de la costa y de todos aquellos elementos necesarios para una navegación segura de las embarcaciones que penetren en la bahía. De este modo, se señala la profundidad de la boca del río expresada en pies, la espiga litoral propia de los estuarios, islas, rocas o arrecifes, el banco estuarial (en este caso lateral), así como también el norte verdadero o geográfico y el magnético. El plano registra también el diseño de la planta física de la ciudad por medio del trazado y orientación de sus calles, con una clara regularidad, similar al plano de damero. Sin embargo, es llamativa la nula conexión existente entre la realidad urbana y el contexto natural o geográfico en que se sitúa. En este mismo sentido, ni siquiera se señalan los posibles caminos que podrían ligar al núcleo urbano con el territorio próximo, quedando interrumpidas bruscamente las calles que salen de la ciudad. Notoriamente se puede advertir que la información sobre la realidad urbana, en su esquematismo, pudo tener un origen diverso de aquella sobre el entorno geográfico. Más aún cuando la primera es bastante detallada y específica al señalar predios edificados o significativos al interior de las manzanas. También llama la atención la representación de finos cursos de agua, que salen de la ciudad. Finalmente, otra característica que distingue al plano es su orientación, con el norte hacia abajo, es decir, representativa de quien ve la ciudad desde el mar.

\section{Vínculos académicos y profesionales de Gilliss en Chile}

La elaboración del volumen I del documento de la expedición, como de la cartografía que lo acompaña, es producto del trabajo de recopilación de información que el teniente Gilliss efectuó durante su permanencia en el país, así como también en gran medida de los vínculos académicos y profesionales que forjó con intelectuales y científicos radicados en Chile, lo cual resulta natural en un hombre de ciencias, como lo era Gilliss. En este contexto, la figura de Gilliss debe también ser evaluada en relación a su contribución a la formación de la identidad de Chile como nación. En primer lugar, por haber reunido en un solo volumen, un compendio de las descripciones gráficas y escritas del país, más actualizadas del momento, y haberlas publicado utilizando los medios más sofisticados de la época, tanto para producir como para reproducir imágenes; y por dar a conocer al mundo este cúmulo de nuevo conocimiento, que, en este sentido, sólo rivaliza con la publicación de la extensa y erudita obra de Claudio Gay, que se había publicado tan sólo un año antes. En segundo término, por dar una condición de cuerpo al conjunto de intelectuales y científicos que actuaban en el país, en la tarea de construir una imagen completa y verosímil de sus características físicas y culturales. En efecto, la revisión de su documento nos permite asistir a esta reunión de grandes hombres del siglo XIX, a través de las muchas referencias que realiza sobre los autores en los que se apoyó para dar forma a su propia interpretación de lo que era el país. Entre estos científicos destaca el naturalista francés Claudio Gay (1800-1873), con quien si bien no tuvo un contacto directo, dado que al momento de llegar la expedición astronómica norteamericana a

12 Colección Biblioteca Nacional. MC: MC0013819. 
Chile en 1849 vivía en París y estaba publicando su magna obra Historia Física y Política de Chile, y finalizando la cartografía general y de las provincias del país que conformarían su Atlas. Pero, sin embargo, sí pudo conocer sus escritos que comenzaron a circular en Chile a partir de 1844, fecha de publicación del primer cuadernillo de su trabajo compuesto por 130 páginas. De igual modo, Gilliss pudo acceder a ella, mediante una donación que le hizo llegar la Universidad de Chile a proposición de su rector Andrés Bello en 1850, consistente en los primeros ocho volúmenes de su obra, como reconocimiento de la labor que estaba llevando a cabo en el país, en especial por el desarrollo de las ciencias ${ }^{13}$. Lo anterior se lo hace saber Andrés Bello a Gilliss, en carta de fecha 25 de mayo de ese mismo año, donde le dice:

Conocedor el Consejo de esta Universidad del interés con que Usted mira todo lo concerniente al conocimiento científico de Chile, y deseoso de manifestarle de algún modo el aprecio que hace de su benévola disposición a contribuir al programa de las ciencias en nuestro país, me ha encargado de transmitir a usted, los 8 tomos, que con las correspondientes láminas tengo el honor de poner a su disposición, de la Historia Física y Política de Chile que actualmente está escribiendo el naturalista Don Claudio Gay"14.

Por otra parte, qué duda cabe, Gilliss tuvo acceso a los borradores de los mapas de Gay, copia de los cuales había entregado el científico francés al ministro de Justicia e Instrucción Pública Manuel Montt ${ }^{15}$, antes de partir a París. Lo anterior queda de manifiesto a raíz de algunas observaciones que comenzaron a efectuarse a los mapas de Gay, una vez publicados en 1854, éste se hace cargo de tales críticas, y en carta que le envía a Manuel Montt desde París, en 1856, alude a la observación que en su oportunidad le hiciera Gilliss sobre el valor de las coordenadas geográficas dadas para la ciudad de Santiago, manifestándole Gay a Montt lo siguiente:

"Por desgracia para mí carta de la provincia de Santiago fíe en las observaciones de ocultación de los satélites de Júpiter de los sabios Bauzá y Malaspina, observaciones que había podido procurarme en España, y por error que no era presumible presumir en esos hábiles astrónomos, mi longitud de Santiago se encuentra algunos minutos más al Oeste, error que se ha extendido a diversos puntos de los alrededores, según me lo comunicó Mr. Gilliss..." (Greve, 1946: 14).

De lo anterior se deduce que, a través de la obra de Gay, estuvieron en contacto, y que Gilliss le dio a conocer su observación. Debemos tener en cuenta que una de las primeras mediciones que realizó Gilliss en Santiago para instalar el Observatorio Astronómico en el Cerro Santa Lucia, fue determinar las coordenadas geográficas del lugar, las que fueron calculadas en $33^{\circ} 26^{\prime}$ de Latitud Sur y $70^{\circ} 38^{\prime}$ de Longitud Oeste. Por su parte, con anterioridad Claudio Gay le había asignado a Santiago los valores de $33^{\circ} 27^{\prime}$ de Latitud Sur y $70^{\circ} 40^{\prime}$ de Longitud Oeste (Stuardo, 1973: 514).

\footnotetext{
En sesión del Consejo de la Universidad de Chile, celebrado el 23 de febrero de 1850, se acuerda enviarle de regalo los primeros ocho tomos de la obra de Claudio Gay a Gilliss. Anales de la Universidad de Chile, 1850, p. 77.

14 Carta de Andrés Bello a Gilliss. 25 de mayo de 1850. Washington: National Archives, Records of the United States Naval Astronomical Expedition to the Southern Hemisphere.

15 Dicha información se la hace saber Claudio Gay al Ministro de Justicia e Instrucción Pública Manuel Montt, en carta fechada en París en 1843 , antes los requerimientos del gobierno por disponer a la brevedad de la cartografía comprometida para fines de la administración del territorio. Le hacía presente que, como aún no terminaba la cartografía definitiva, "mientras tanto, el Supremo Gobierno puede hacer uso de lo que he dejado en el ministerio de US, pues es bastante exacta y más que suficiente para cualquier operación administrativa".
} 
Gilliss demuestra también estar al tanto del trabajo que realizaba Claudio Gay para el gobierno de Chile y así se lo hace saber al profesor alemán Scholtz en carta fechada el $1^{\circ}$ de Abril de 1852, en relación con el desarrollo de la historia física y natural del país, cuando le dice:

"Next a French naturalist comes to Chile about 1833 or ' 34 who soon obtained employment by the government by the advice of the University. He has been charged to investigate and make known at its expense it's political and natural history. The first has been completed in five handsome volumes of Botany and one of Zoology illustrated with 150 superb folio plates colored. Mr. Gay the naturalist referred to is now in Paris superintending the publication of the remaining portions; but I have no knowledge how expensive the work will be. Without pretending to any knowledge of his scientific acquirements [sic], I have no hesitation in saying that the work is highly honorable to the government of Chile"16.

Otro de los científicos con los que interactuó Gilliss, pero ahora de manera personal, fue con Amado Pissis (1812-1889), geógrafo y geólogo de nacionalidad francesa que llegó a Chile proveniente de Bolivia, en viaje para regreso a su país. Al saber de su estadía, las autoridades del gobierno de Chile, conscientes de la necesidad de disponer de información acerca de los recursos naturales del país, lo contactaron en 1848 para solicitarle la realización de un levantamiento que describiera las características geológicas y mineralógicas del territorio nacional.

La relación de Gilliss con Pissis, tuvo su origen en el hecho de que éste último disponía al momento del arribo de la expedición astronómica a Santiago de Chile, de una serie de datos de las características topográficas del país en general y de manera muy especial de la provincia de Santiago, información que era de sumo interés para la localización del observatorio que Gilliss deseaba emplazar. De hecho, ya en 1850, Pissis disponía de un levantamiento original de la Provincia de Santiago, el que como se señaló anteriormente puso a disposición de Gilliss. No hay que olvidar que para la instalación del observatorio se tuvieron en consideración el Cerro Blanco, al norte de la ciudad de Santiago, el Llano de Subercaseaux, en el área sur y el Cerro Santa Lucía, en el centro de la ciudad, siendo este último lugar el que fue seleccionado en definitiva para ello. En este sentido, era de vital importancia conocer el entorno geográfico de la ciudad de Santiago.

Por otro lado, para Pissis la llegada de Gilliss con un instrumental de última generación: (telescopio ecuatorial, círculo meridiano, barómetros, etc.), era un motivo más que suficiente para entablar una relación profesional, sobre todo cuando Pissis requería para determinar las coordenadas geográficas de los puntos de inicio de sus líneas de bases, tan necesarias para aplicar el método de la triangulación geodésica que propuso para su levantamiento cartográfico del territorio nacional, el contar con instrumentos similares y, obtener así datos de la mayor precisión. Para ello no dudó en solicitar la ayuda de Gilliss en la adquisición de dichos aparatos, quien escribe a los fabricantes de instrumentos londinenses Jones \& Darrows, en noviembre de 1850, cuyo texto es el siguiente:

"Sir, I have been requested by Senior Pissis and Engineer employed in making a topographical \& geological map of the Republic for the government of Chili, to obtain for him an

Carta de Gilliss a Scholtz, 1 de Abril de 1851. Washington: National Archives, Records of the United States Naval Astronomical Expedition to the Southern Hemisphere. 
altitude \& azimuth instrument of the same dimensions as that furnished for the use of the Astr. Expedition, which I will thank you to ship, with its tripod at the earliest possible day to the care of Messrs. Huth, Gruning \& Co Valparaiso. Be pleased to forward at the same time a pair of bar magnets that will serve for reversing the poles of dipping needles, paying especial attention to the tempering of the metal, as those sent me by Mr. Barrow have entirely last their force on that account. Should not the triangle have been sent the occasion will be suitable for forwarding it. On receipt of a bill of lading a draft will be sent for the amount. Very Respectfully, J.M.G"17.

Por otra parte, Gilliss hace mención de Pissis en cartas que envió a personeros de Europa y Estados Unidos, Scholtz y Smith, con los que mantiene intercambio epistolar. Se refiere a él como "ingeniero" de profesión y al trabajo que estaba efectuando en Chile. Al primero de ellos, le informa en carta fechada el $1^{\circ}$ de abril de 1851, acerca del desarrollo científico chileno, donde menciona el trabajo que lleva adelante Pissis por encargo del gobierno de Chile, haciendo especial referencia al estudio de la provincia de Santiago, área en la que se buscaba información confiable de uso público, cuyo levantamiento, relata, había sido tan exitoso que le encargaron realizar otros para diversas provincias, por lo que se encontraba en ese momento realizando el de la provincia de Valparaíso. Gilliss detalla que el estudio había sido realizado trigonométricamente, habiendo medido para ello una línea base en el llano del Maipo y extendiendo a partir de ella los triángulos para efecto de la triangulación trigonométrica. Gilliss señala también que la mayoría de las alturas fueron determinadas utilizando barómetro. Y de igual modo, indica que el mapa de la provincia de Santiago, se encontraba en ese momento en manos del grabador Narciso Desmadryl, quien habría cobrado una elevada suma de dinero por la litografía, ya que sabía que no había nadie más que la pudiera realizar ${ }^{18}$. El texto de la carta señala lo siguiente:

"Not have they forgotten the wants of geographical and geological science. Two years ago, Mr. A. Pissis a graduate of the Polytechnic school proposed to make a survey of the province of Santiago with a view to obtaining reliable information for public use, an offer which was accepted and which was so satisfactorily executed that he has reviewed direction to make like surveys of the other provinces and is now engaged upon that of Valparaiso, several assistants having been given him among them is Mr. Moësta a former pupil of Dc. Gerling. The survey was conducted trigonometrically [sic] a base having been measured on the plain of Maypo and the triangles thence extended. Most of his heights have been determined by the Barometer which offers special facilities in the summer months owing to the small diurnal tide and the almost total absence of extraordinary fluctuations. His map would now have been in the publisher's hands, but Mr. Desmadryl the engraver like every other foreigner who comes feels bound to make the most money in the least time and demands $\$ 5000$ to lithograph it! Well knowing there is no one else to undertake it and the work must eventually fall into his hands." (Carta de Gilliss a Scholtz, $1^{\circ}$ de abril de 1851)"19.

\footnotetext{
Carta de Gilliss a Jones \& Darrows, noviembre de 1850. Washington: National Archives, Records of the United States Naval Astronomical Expedition to the Southern Hemisphere.

18 El mapa de la Provincia de Santiago fue grabado en piedra en la ciudad de Edimburgo, Gran Bretaña, Casa de Adán y Carlos Black, el año 1857 , el de las provincias de Valparaíso y Aconcagua en el año 1859.

19 Carta de Gilliss a Scholtz. Op. Cit.
} 
Otra de las personas con las que Gilliss tuvo una relación personal, fue Allan Campbell (18161894), ingeniero de origen norteamericano que llegó al país para participar en la construcción del ferrocarril de Caldera a Copiapó, obra que estaba a cargo de William Wheelwright. Gilliss entró en contacto con Campbell cuando éste visitó el norte de Chile, ocasión en la que Gilliss se interiorizó de las características del ferrocarril que unía Caldera con Copiapó. Esta amistad se intensificó años más tarde, a raíz de un intercambio epistolar, cuando comenzó a concretarse la idea de construir un ferrocarril que conectara las ciudades de Santiago y Valparaíso, en la década del 50 del siglo XIX, y el gobierno contrató a Campbell para elaborar el diseño de las posibles rutas de su trazado. Luego de analizar varias alternativas, Campbell se inclinó, finalmente, por una ruta que partía en Valparaíso y recorría Viña del Mar, Concón, Quillota y luego cruzaba hacia Santiago por el paso Tabón (Thomson, 2010: X). Con la finalidad de fundamentar el diseño de su propuesta en 1851, Campbell realizó importantes trabajos de geomensura por lo que al concluir su Informe sobre el proyecto de Ferrocarril de Valparaíso a Santiago, incorporó estos antecedentes en el texto, específicamente en el capítulo «Reconocimiento y descripción topográfica" de la probable ruta, donde aportó valiosa información sobre la situación de los puntos geográficos involucrados en el proyecto, referencias de las que más tarde se valió Gilliss para la confección de su documento y de la cartografía que lo acompaña, en especial el Mapa de Chile General, donde expresa claramente que una de las fuentes utilizadas es Allan Campbell. De igual modo, en el mapa de la Provincia de Santiago, elaborado por Gilliss, se incorporó el diseño de la línea del ferrocarril proyectada de Santiago a Valparaíso, claro que ahora basado en un proyecto de trazado que pasaba por las cercanías de la ciudad de Melipilla.

Finalmente, otro de los hombres de ciencia destacados, con el que Gilliss interactuó directamente fue Ignacio Domeyko (1802-1889), en virtud que, desde el arribo de la expedición naval astronómica a Chile, en 1849, Domeyko se desempeñaba como profesor y miembro del consejo universitario de la Universidad de Chile, centro universitario con el que Gilliss mantuvo estrechos vínculos académicos y profesionales durante toda su permanencia en Chile. En dicha relación, Domeyko jugó un papel fundamental desde la llegada hasta la partida de la expedición astronómica, cumpliendo una serie de encargos que le fueron encomendados por la universidad y el rector de la misma.

La vinculación de Domeyko con Gilliss no estuvo relacionada con la cartografía que acompaña el documento que comentamos, aunque valoró de manera muy positiva el mapa general del país que lo acompaña, del que dice que aunque es "copiado de todos los mapas parciales que se han publicado hasta ahora y sin duda (es) el mejor que tenemos" (Domeyko, 1857: 673), sino que su proximidad es con el trabajo científico que realizaron de manera conjunta en beneficio del desarrollo de la ciencia del país, lo que se tradujo entre otros aspectos en salidas a terreno, generación de información y, muy especialmente, en la negociación que se llevó a cabo para la compra y adquisición por parte del gobierno de las instalaciones del Observatorio Astronómico que Gilliss trajo a Chile, una vez que la expedición concluyó su estadía en el país, situación en la que Domeyko jugó un papel fundamental (Ryn, 2016: 291-292).

Sin embargo, hay un aspecto que tiene que ver con la descripción del territorio nacional que Gilliss hace sobre Chile en su escrito y acerca del cual Ignacio Domeyko escribió una reseña en la Revista Ciencias y Letras del año 1857, titulada "Estudios Geográficos sobre Chile". con motivo de la publicación del primer tomo de la obra de Gilliss, aparecida en Washington en 1855, Domeyko 
se refiere a ella de una forma muy crítica, esencialmente por el método empleado en su realización y la cantidad de errores que encuentra en sus páginas, en especial sobre la geografía física del texto, señalando que un estudio sobre esta materia, se debía apoyar en primer término en los aspectos geológicos del territorio, fundamento de la geomorfología, para luego continuar con la hidrología a la que le debía seguir la meteorología. A partir de las dos últimas, se debía incursionar en el conocimiento de sus productos naturales, cuyo estudio a su vez, conduce a la división político-administrativa. Por lo que Domeyko concluye que, en el estado actual de la ciencia geográfica, para poder hacer un estudio algo profundo de la geografía de un país, era indispensable seguir este orden. No obstante, a pesar de lo anterior, valora las observaciones meteorológicas realizadas por Gilliss que tenían el mérito de haber sido observadas por él personalmente; como también la información estadística y la revisión bibliográfica que ella contenía; así como una serie de elementos importantes del territorio nacional que merecían una atención especial, para su conocimiento y valoración, sobre todo, señala Domeyko, por parte de los jóvenes (Domeyko, 1857: 674).

\section{Conclusiones}

Las representaciones cartográficas que ilustran el documento confeccionado por Gilliss, en su descripción de las características geográficas del territorio chileno, no corresponden a levantamientos originales de la expedición, sino que se trata de mapas compilados, es decir, tomados de otros autores y adecuados a sus propósitos. Sin embargo, no son simples copias, y tienen el mérito de haber sido apropiadas por Gilliss, mediante la aplicación de métodos y técnicas cartográficas, en uso en el momento de su publicación. Así, por ejemplo, es lo que ocurre con la utilización que Gilliss hace del meridiano de Greenwich, como referencia para indicar la línea cero o de origen de la longitud en sus mapas, tanto en el General de Chile y Provincia de Santiago, así como también en el Plano de la ciudad de Santiago. En relación a esto, se debe tener en consideración que los mapas de apoyo utilizados en la elaboración de los dos primeros, el de Claudio Gay y el de Amado Pissis, emplean como referencia los meridianos de Cádiz y del Cerro Santa Lucía, respectivamente, mientras que en el tercero, el plano de Santiago levantado por los oficiales de la Academia Militar de Santiago, la longitud quedó referida a Greenwich. La situación anterior, es digna de destacarse porque el meridiano de Greenwich sólo fue ratificado universalmente en 1884, lo que es indicativo del carácter pionero de la obra de Gillis, en esta materia. Muy posiblemente, este hecho está determinado por el valor de la longitud geográfica del Observatorio Astronómico de los Estados Unidos localizado en Washington, cuyo referente es el Observatorio Astronómico de Inglaterra ubicado en la localidad de Greenwich. En este mismo orden de cosas, otra modificación cartográfica de importancia que se puede advertir, en especial en el mapa de la Provincia de Santiago de Gilliss, es el método que utilizó para representar el relieve, donde utiliza las normales de pendiente y expresa las cotas de altitud en pies. En cambio el mapa de Pissis, su referente, emplea las normales de sombra para el relieve y la altitud están expresadas en metros, lo que refuerza la idea que no son simples copias, sino que hay además del trabajo de compilación significativas adaptaciones cartográficas.

En cuanto a los planos, tanto el de Constitución y Puerto en la Boca del Río Maule como el de Valparaíso del documento de Gilliss, en los que a pesar de no indicarse su fuente, es de suponer que se deben haber fundado en levantamientos coetáneos para su realización. Lo anterior no desmerece su valor en absoluto, por el contrario tienen la virtud de resaltar determinados lugares que 
los miembros de la expedición consideraron significativos del territorio nacional para refrendar su descripción geográfica.

Para la confección del documento mismo, hay que destacar que fueron muy importantes los vínculos académicos y profesionales que forjó el teniente Gilliss durante los tres años que permaneció en Chile, para cumplir con el objetivo central de su misión, en que fue necesario asesorarse de aquellas personas que le facilitarían su cometido, especialmente en cuanto al lugar donde poder emplazar el observatorio astronómico que traía la expedición, así como también para satisfacer su propia inquietud intelectual por conocer y posteriormente divulgar su visión del territorio chileno, a través del texto en que abordó diversas materias de carácter político, económico y social. El escrito que resultó al concluir su quehacer da cuenta de haber cumplido con ambos propósitos.

Sin embargo, como cualquier trabajo de esta naturaleza estuvo sometido al análisis de sus pares, algunos hicieron notar sus virtudes y otros sus debilidades o ambas cosas a la vez. Entre los primeros, se encuentra el propio Alexander von Humboldt quien utilizó la información sobre Chile y lo citó en su obra el Cosmos y, entre los segundos, encontramos a Ignacio Domeyko, hombre de ciencia con quien Gilliss compartió e intercambió valiosa información sobre el país durante su estadía. La principal razón de las críticas de Domeyko se encuentra en que no compartió el método seguido por Gilliss para presentar y analizar la naturaleza física del país que describe en su texto, por el hecho de no seguir un orden sobre lo que, en ese momento, los geógrafos físicos postulaban que era la forma adecuada de hacerlo científicamente, así como también por haber cometido una serie de errores referentes a la localización de los fenómenos y accidentes geográficos, como consecuencia de no haber tenido, según él, un contacto directo con muchos de ellos. También fue un antecedente importante, que de algún modo influyó en el ánimo de Domeyko, hombre profundamente católico, que las críticas de Gilliss hacia el país, especialmente en aquellas materias relacionadas con el modo de vida de sus habitantes rurales, la iglesia católica, la forma de gobierno y sus instituciones, las considerará bastantes injustas para un país que tan bien lo había acogido.

La capacidad de Gilliss de recolectar información oportuna y actualizada con respecto a Chile, para contextualizar adecuadamente su informe científico, y específicamente en términos de su cartografía, aquella que estaba en pleno proceso de producción, convierten a su obra en un gran compendio de lo que era Chile a mediados del siglo XIX. Pocas veces se ha prestado atención a esta importante cualidad del trabajo de Gilliss, pues desde la actualidad su aportación tiende a confundirse e invisibilizarse con la realizada por los diversos hombres de ciencia que en aquella época se encontraban trabajando en el país. Sin embargo, la virtud de Gilliss consistió en su capacidad de reunir, en un solo volumen, una gran cantidad de información inédita sobre el país, que permitió que Chile se diera a conocer en el contexto mundial. Como también se debe señalar, que ese conjunto de información fue organizado, reproducido e incluso confeccionado especialmente por una mente adiestrada y formada en una específica disciplina: la astronomía, que le impuso un rigor intrínseco, expresión de una particular manera de entender el mundo. Estar atentos a estas cualidades, es fundamental para sopesar, en la actualidad, el aporte de Gilliss a la cultura nacional. Incluso, considerar su obra como una contribución a la conformación de Chile como Estado y nación. Haber reunido, en el caso específico de su capital, Santiago, una descripción rigurosa de sus cualidades urbanas, sociales y culturales, sumado al hecho de haber realizado 
un plano de planta urbana que reforzaba esta aproximación, y un panorama que la describía detallada y globalmente como realidad visual, fue, sin duda, el gran mérito de Gilliss. Más aún si a lo anterior agregamos el plano de provincia de Santiago, el cual, como ya vimos, nos muestra la creciente complejidad que revestía la constitución de una ciudad a mediados del siglo XIX, que además tenía el añadido de proyectarse como capital de una república naciente. Esta sola noción de capitalidad, ya nos alerta sobre la necesidad que existía en aquel momento de escrutarla, reconocerla y asumirla en esta nueva condición.

\section{BIBLIOGRAFÍA}

BARTHES, ROLAND. La Torre Eiffel. Textos sobre la imagen. Buenos Aires: Paidós Comunicación, 2009.

DOMEYKO, IGNACIO. Estudios geográficos sobre Chile. Revista de Ciencia y Letras, Santiago de Chile, 1857, p.632-674.

ESPINOZA, LEONARDO. "La cartografía histórica de Santiago, desde la colonia hasta Ansart, 15411875". En: El catastro urbano de Santiago. Orígenes, desarrollo y aplicaciones. Santiago de Chile: Ilustre Municipalidad de Santiago. Dirección de Obras Municipales, 2008.

ERRÁZURIZ, ANA MARÍA. Los primeros avances geográficos para el reconocimiento del territorio nacional (1810 - 1860). Boletín Informativo Instituto Geográfico Militar, 1981, II trimestre, p. 12-16.

GILLISS, JAMES MELVILLE. The U.S. Naval Astronomical Expedition to the Southern Hemisphere during the Years 1849-50-51-52. Washington: A. O. P. Nicholson Printer, Vol. I, 1855.

GILLISS, JAMES MELVILLE. La expedición astronómica y naval de los Estados Unidos al Hemisferio Sur durante los años 1849 '50 '51 '52. Santiago de Chile: Septiembre Ediciones, DIBAM, 2017.

GONZÁLEZ, JOSÉ, I. Primeros levantamientos cartográficos generales de Chile con base científica: los mapas de Claudio Gay y Amado Pissis. Revista de Geografía Norte Grande, 2007, № 38, p. 21-44.

GREVE, ERNESTO. Don Amado Pissis y sus trabajos geográficos y geodésicos en Chile. Santiago: Imprenta Universitaria, 1946.

HIDALGO, GERMÁN (1). Un astrónomo en Chile. En: Gilliss, James Melville; La expedición astronómica naval de los Estados Unidos al Hemisferio Sur durante los años 1849, 50,51 y 52. Santiago: Septiembre Ediciones. DIBAM, 2017, p. 9-23.

HIDALGO, GERMÁN (2). La ciudad como problema de representación y conocimiento. La mirada urbana de la expedición naval astronómica norteamericana de J. M. Gilliss. Revista 180, Facultad de Arquitectura, Arte y Diseño U.D.P. 2017, №39, p. 1-14. (revista digital). 
HIDALGO, GERMÁN; ROZAS, J.; STRABUCCHI, W. (3). Santiago de Chile en torno a 1850. El plano de planta urbana como instrumento revelador de su forma general. Revista $A R Q, 2017$, No 96, p. 108-123.

HUMBOLDT, ALEXANDER VON, Cosmos. Ensayo de una descripción física del mundo. Madrid-Santiago: Consejo Superior de Investigaciones Científicas, España. Centro de Investigaciones Diego Barros Arana. DIBAM, 2011.

JOLY, FERNAND. La cartografía. Madrid: Editorial Ariel, 1979.

MARTÍNEZ, RENÉ. Santiago de Chile 1850-1875. Los planos de su historia. Siglo XVI a XX. De aldea a metrópolis. Santiago de Chile: Centro de Investigaciones Diego Barros Arana - I. Municipalidad de Santiago, 2007.

PRATT, MARY LOUISE. Ojos imperiales. Literatura de viajes y transculturación. México: Fondo de Cultura Económica, 2010.

ROSAS, J.; STRABUCCHI, W.; HIDALGO, G. y GONZÁLEZ, D. “Santiago de Chile 1850-1975: Nuevas periferias y forma general, en: revista Anales del Instituto de Arte American e Investigaciones Estética, Universidad de Buenos Aires, № 47 (Bordes Metropolitanos), 2017, p. 15-30.

RYN, JAN ZDZISLAW. Ignacio Domeyko. La vida y la obra. Santiago de Chile: Editorial Universitaria, Ediciones UC, 2016.

SAGREDO, RAFAEL; GONZÁLEZ, JOSÉ IGNACIO. La expedición Malaspina en la frontera austral del imperio español, Santiago de Chile: Centro de Investigaciones Diego Barros Arana, Editorial Universitaria, 2004.

SAGREDO, RAFAEL (1). (Editor). Ciencia-Mundo. Orden republicano, arte y nación en América. Santiago de Chile: Centro de Investigaciones Diego Barros Arana, Editorial Universitaria, 2010.

SAGREDO, RAFAEL (2). El atlas de Gay. La representación de una nación. En: Atlas de la Historia Física y Política de Chile. Santiago: Cámara Chilena de la Construcción, Pontificia Universidad Católica de Chile, Dirección de Bibliotecas, Archivos y Museos. Lom Ediciones, 2010.

SAGREDO, RAFAEL (3). La ruta de los naturalistas. Santiago: Corporación Patrimonio Cultural de Chile, Larrain Vial. Fyrma Gráfica. 2012.

SCHRIMPF, ANDREAS. An international campaign of the 19th century to determine the solar paraIlax. The US Naval expedition to the Southern Hemisphere, 1849-1852. En: The European Physical Journal B, 2014 (https://arxiv.org/abs/1402.1945).

SOLA-MORALES, MANUEL. "La identidad del territorio". En: Quaderns d'Arquitectura i Urbanisme, Barcelona, 1980. 
STUARDO, CARLOS. La vida de Claudio Gay. Estudios y Documentos. Santiago de Chile: Fondo Histórico y Bibliográfico José Toribio Medina y Editorial Nascimiento, 1973.

THOMSON, IAN. Allan Campbell y los ingenieros del ferrocarril entre Santiago y Valparaíso. En: Campbell Allan. Documentos relativos al proyecto de un ferrocarril entre Santiago y Valparaíso. Santiago de Chile: Biblioteca Fundamentos de la Construcción de Chile, CChC, Vol. 36, 2010.

UNIVERSIDAD DE CHILE. Anales de la Universidad de Chile. Acta de las sesiones del Consejo Universitario, años 1849, 1850, 1851. 